Opinion

\title{
Avian electrocardiography: a simple diagnostic tool
}

\section{Opinion}

In veterinary medicine, avian cardiology is one of the previously neglected and presently developing areas in India. Until the heart decompensates, cardio vascular diseases are undetectable in birds. The electrocardiography is one of the non-invasive and cost-effective procedures to detect the heart rate, detect arrhythmias, cardiac chamber enlargement, and electrical conductance abnormalities. ${ }^{1}$ Much literature is available on the ECG in pet, farm animals and recently in avian species. ${ }^{2-5}$ Clinical examination is the primary assessment to suspect the cardiac involvement and started from the visualization of the breathing pattern, auscultation of thorax and heart for abnormal findings. ${ }^{6}$

For regular electrocardiography analysis of birds, ECG machine with a speed above the $50 \mathrm{~mm} / \mathrm{sec}$ needs to select. If the speed of the machine at slower speeds the ECG waveforms are too close together and it is difficult to analysis. ${ }^{5}$ While recording the ECG, needle electrodes placed should be placed subcutaneously, onto which the alligator clips are attached. In few birds, directly alligator clips alone can be attached to the birds. To prevent the artifact and skin damage, application of gel is recommended while recording ECG. ${ }^{4}$ Anaesthesia is not recommended while tracing the electrocardiography unless required. It is always advised to collect the ECG without any anaesthesia which will be facilitated during the interpretation. In electrocardiography, most of the birds show the inverted QRS wave in lead II which indicative of negative mean electrical axis. To record the regular parameters standard bipolar limb lead II is considered as the standard lead for analysis. The morphology of P wave, PR-interval, QRS complexes, ST-segment, T wave, QT-interval and U wave were analyzed in lead $\mathrm{II}^{4,7}$ (Figure 1).

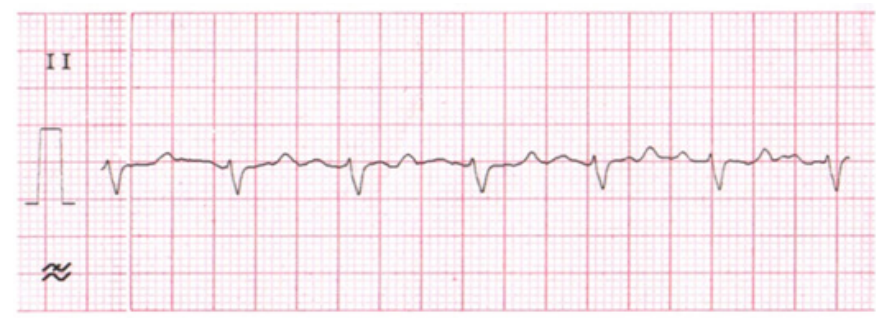

Figure I Electrocardiography in the apparently healthy bird (Lead II).

Most common recordable avian electrocardiography abnormalities including: ${ }^{7,8}$
a. Sinus tachycardia
b. Sinus bradycardia
c. Sinus arrhythmia
d. Atrial fibrillation
e. Atrial flutter
f. Sinus arrest
g. Sinoatrial block
h. Right bundle branch block

Volume 2 Issue 5 - 2017

\author{
B Sudhakara Reddy, S Sivajothi \\ SriVenkateswara Veterinary University, India
}

\begin{abstract}
Correspondence: Bhavanam Sudhakara Reddy, College of Veterinary Science, Proddatur, Pin: 5 I 6360, YSR District, Sri Venkateswara Veterinary University, Andhra Pradesh, India, Email bhavanamvet@gmail.com
\end{abstract}

Received: December 03, 2017 | Published: December 20, 2017

i. Left bundle branch block

j. Wandering pacemaker

k. Atrial tachycardia

1. Atrio ventricular dissociation

m. Supra ventricular tachycardia

n. Ventricular premature contractions

o. Ventricular tachycardia

p. Ventricular fibrillation

q. Ventricular flutter

r. First-degree heart A-V block

s. Second-degree heart A-V block

\section{Acknowledgements}

None.

\section{Conflict of interest}

The author declares no conflict of interest.

\section{References}

1. Machida N, Aohagi Y. Electrocardiography, heart rates, and heart weights of free-living birds. J Zoo Wildl Med. 2001;32(1):47-54.

2. Reddy BS, Reddy LSSV, Raju KGS, et al. Electrocardiographic studies in adult Osmanabadi goats. Photon. 2014;115:333-337.

3. Reddy BS, Sivajothi S. Vital and electrocardiographic parameters in domestic New Zealand white pet rabbits. International Journal of Livestock Research. 2017;7(10):86-91.

4. Reddy BS, Reddy PA, Venkatasiva kumar R, et al. A study on electrocardiographic patterns in turkeys (Meleagris gallopavo). Inter $J$ Vet Sci. 2016;5(2):79-82.

5. Papahn AA, Naddaf H, Rezakhani A, et al. Electrocardiogram of homing pigeons. J Appl Anim Res. 2006;30(2):129-132.

6. Reddy BS, Venkatasivakumar R, Reddy LSSV, et al. Analysis of base apex lead electrocardiograms of adult buffaloes. Journal of Dairy Veterinary Animal Research. 2015;2(6):00058. 
7. Miller MS. Avian ECG and the use of ECG in poultry research and clinical practice. USA: Proceedings Mid-Atlantic States Avian Conference; 1987.
8. Lumeij JT. Avian cardiology: part II-electrocardiography. Association of Avian Veterinarians Annual Conference Proceedings; 2003. p. 331-38. 